\title{
O processo de implantação do Parque Estadual do Cocó, Fortaleza (CE): conflitos e perspectivas
}

The implementation process of the Parque Estadual do Cocó, Fortaleza (CE): conflict and prospects

SOUSA $^{1}$, É.N.C.; SANTOS ${ }^{2}$, F.A.

erica.costa@aluno.uece.br

\begin{abstract}
Resumo
Há nos espaços urbanos, atualmente, uma acentuada geração de conflitos, por conta das divergências de interesses de ordem social, política, econômica e também cultural. Desde a criação do Sistema Nacional de Unidades de Conservação (SNUC), no ano 2000, a problemática na implantação de Unidades de Conservação (UC's) tem se intensificado, fruto de vários anseios e frustrações no confronto de ideias. O presente artigo constitui um trabalho que se insere dentro do debate acerca do tema das UC's e busca analisar os conflitos socioambientais, gerados pela proposta de delimitação física do Parque Estadual do Cocó, em Fortaleza (CE). Diante da problemática da efetivação da UC enquanto unidade legal, o estudo concluiu dentro do contexto de Fortaleza, um favorecimento ao setor imobiliário, tendo em vista as potencialidades do ambiente, em detrimento das comunidades tradicionais, considerando que ambos se utilizam de maneira completamente diferente desses espaços.
\end{abstract}

Palavras-chave: Unidades de Conservação; áreas urbanas; conflitos socioambientais.

\begin{abstract}
There are in the urban spaces, currently a marked generation of conflicts, due to the divergence of interests social, political, economic and also cultural. Since the establishment of the National System of Conservation Units (SNUC) in 2000, issues in the conservation units (UCs) deployment has intensified as a result of various longings and frustrations in the confrontation of ideas. This article is a work that falls within the debate on the subject of UCs and seeks to analyze the environmental conflicts generated by the proposed physical demarcation of the Parque Estadual do Cocó, in Fortaleza (CE). On the issue of realization of UC as a legal unit, the study concluded within the context of Fortaleza, a certain favoring of real estate sector, in view of the environmental potentials, to the detriment of traditional communities, considering that both use quite differently these spaces.
\end{abstract}

Keywords: Conservation units; urban areas; socioenvironmental conflicts.

\section{INTRODUÇÃO}

O crescimento desordenado da malha urbana, o aumento das populações e a gradativa necessidade por mais recursos naturais têm impactado de forma preocupante o meio ambiente, situação esta, que implica diretamente na diminuição da qualidade de vida nas cidades. Nessas circunstâncias, a temática ambiental traz à tona discussões acerca de uma consciência ecológica, diante da devastação da natureza, principalmente nos grandes centros urbanos.

A Constituição Federal, em seu Artigo 225, dispõe que o meio ambiente é um bem de uso comum do povo e um direito de todos os cidadãos, das gerações presentes e futuras, estando o Poder Público e a coletividade obrigados a preservá-lo e a defendê-lo (BRASIL, 1988). Nessa perspectiva foi instituído o Sistema Nacional de Unidades de Conservação (SNUC), com a promulgação da Lei $n^{\circ}$ 9.985, de 18 de julho de 2000, para a criação e gestão de Unidades de 
Conservação (UC's) com o objetivo de manutenção dos recursos naturais, a partir da propagação da visão de desenvolvimento sustentável (BRASIL, 2000). Para fins legais, o SNUC entende como Unidade de Conservação espaço territorial e seus recursos ambientais, com características naturais relevantes, legalmente instituído pelo Poder Público, com objetivos de conservação e limites definidos, ao qual se aplicam garantias adequadas de proteção.

Ainda de acordo com as concepções do SNUC, as UC's dividem-se em duas categorias, quais sejam: área proteção integral, que têm por objetivo preservar a natureza, sendo admitido apenas o uso indireto dos seus recursos naturais, com exceção dos casos previstos nesta Lei; e área de uso sustentável cujo objetivo central é compatibilizar a conservação da natureza com o uso equilibrado de parcela dos seus recursos naturais, assim como descrito no Art. $7^{\circ}, \S 1^{\mathrm{o}}$ e $\S 2^{\circ}$, respectivamente (BRASIL, 2000).

A categoria Parque é uma UC de proteção integral, no qual a visitação pública está sujeita às normas e restrições estabelecidas no Plano de Manejo da unidade, onde somente podem ser realizadas pesquisas científicas e atividades de educação e interpretação ambiental, de recreação em contato com a natureza e de turismo ecológico, sendo públicos a posse e o domínio destas áreas, devendo a dominialidade privada incluída em seus limites ser desapropriada.

Nesse contexto, insira-se o Parque Ecológico do Cocó (PEC), cuja preservação justificase devido a riqueza de sua fauna e flora, além da importância comprovada para o conforto térmico de Fortaleza. Costa e Ferreira (2009) ressaltam que as áreas verdes são capazes de promover significativas melhorias no ambiente urbano, principalmente no que se refere à redução da poluição atmosférica, à minimização das temperaturas, ao conforto ambiental, atuando, consequentemente, na sua qualidade de vida da população.

O projeto de regulamentação apresentado pelo atual Governo do Estado do Ceará, através da Secretaria do Meio Ambiente do Estado (SEMA), prevê adequação ao SNUC, com proposta de denominação de Parque Estadual do Cocó, com uma área total de 1.050 hectares. Além da área de parque, haverá 316 hectares de Área de Relevante Interesse Ecológico (ARIE), totalizando 1.366 hectares de área protegida.

Formará, segundo a proposta apresentada em audiência pública, um mosaico de áreas protegidas quando somadas a outras UC's já legalmente instituídas, sendo: 1.019,49 ha da Área de Proteção Ambiental - APA da Sabiaguaba; 467,61 ha do Parque Natural das Dunas de Sabiaguaba; 37,80 ha do Parque Linear Adahil Barreto; 15,72 ha da ARIE Municipal Dunas do Cocó; e 12,57 ha da ARIE das Dunas da Cidade 2000; pretende-se, portanto, criar uma rede de áreas protegidas de 2.907,44 hectares (CEARÁ, 2016). 
Nos espaços urbanos há de destacar-se a geração mais acentuada de conflitos no processo de implantação de UC's, por conta das divergências de interesses de ordem social, política, econômica e também cultural. O conflito socioambiental expressa-se como uma luta entre interesses opostos, que disputam o controle dos recursos naturais e o uso do meio ambiente comum. Para (BRITO et al. 2011), conflitos socioambientais, também, configuram-se com a incompatibilidade de interesses sobre o uso do mesmo território ou pela utilização dos recursos naturais entre indivíduos ou grupos independentes.

Os conflitos ambientais relacionados à ocupação de comunidades humanas em UC's ampliam-se nas esferas social, política e jurídica. A partir desse enfoque, algumas pesquisas têm questionado a supremacia e eficácia da categoria "populações tradicionais" para discutir o papel das populações humanas na proteção da natureza (MARTINS, 2012).

Os Povos Tradicionais são reconhecidos pela Política Nacional de Desenvolvimento Sustentável dos Povos e Comunidades Tradicionais (PNPCT), Decreto $n^{\circ}$ 6.040, de 7 de fevereiro de 2007, como grupos culturalmente diferenciados e que se reconhecem como tais, que possuem formas próprias de organização social, que ocupam e usam territórios e recursos naturais como condição para sua reprodução cultural, social, religiosa, ancestral e econômica, utilizando conhecimentos, inovações e práticas gerados e transmitidos pela tradição (BRASIL, 2007).

Percebe-se, portanto, que a proteção ambiental pode ser a solução para uma determinada crise, mas pode ser a causa de outras. A situação vai depender de como a política é negociada com as populações envolvidas e como é construído o conceito de conservação. Desse modo, diante do exposto, procurou-se neste estudo analisar os conflitos socioambientais, gerados pela proposta de delimitação física do Parque Estadual do Cocó, em Fortaleza (CE). Aliado a isso, foram identificados os principais aspectos geoambientais, bem como suas condições atuais de degradação que possam justificar ainda mais a necessidade de preservação dada a importância desses sistemas ambientais. Por fim, pretendeu-se expor as repercussões da regulamentação do Parque Estadual do Cocó no âmbito das comunidades tradicionais e demais agentes envolvidos.

\section{METODOLOGIA}

\section{1 Área de estudo}

O Parque Ecológico do Cocó (PEC), abrange apenas o baixo curso do rio homônimo. Compreende o trecho da BR 116 à foz do rio, localizado no município de Fortaleza, Estado do Ceará (Figura 01). O Rio Cocó faz parte da bacia dos rios do litoral leste cearense, nasce na Serra da Aratanha e passa por três municípios, Pacatuba, Maracanaú e Fortaleza, para desaguar nos limites das praias do Caça e Pesca e Sabiaguaba (CEARÁ, 2016). 


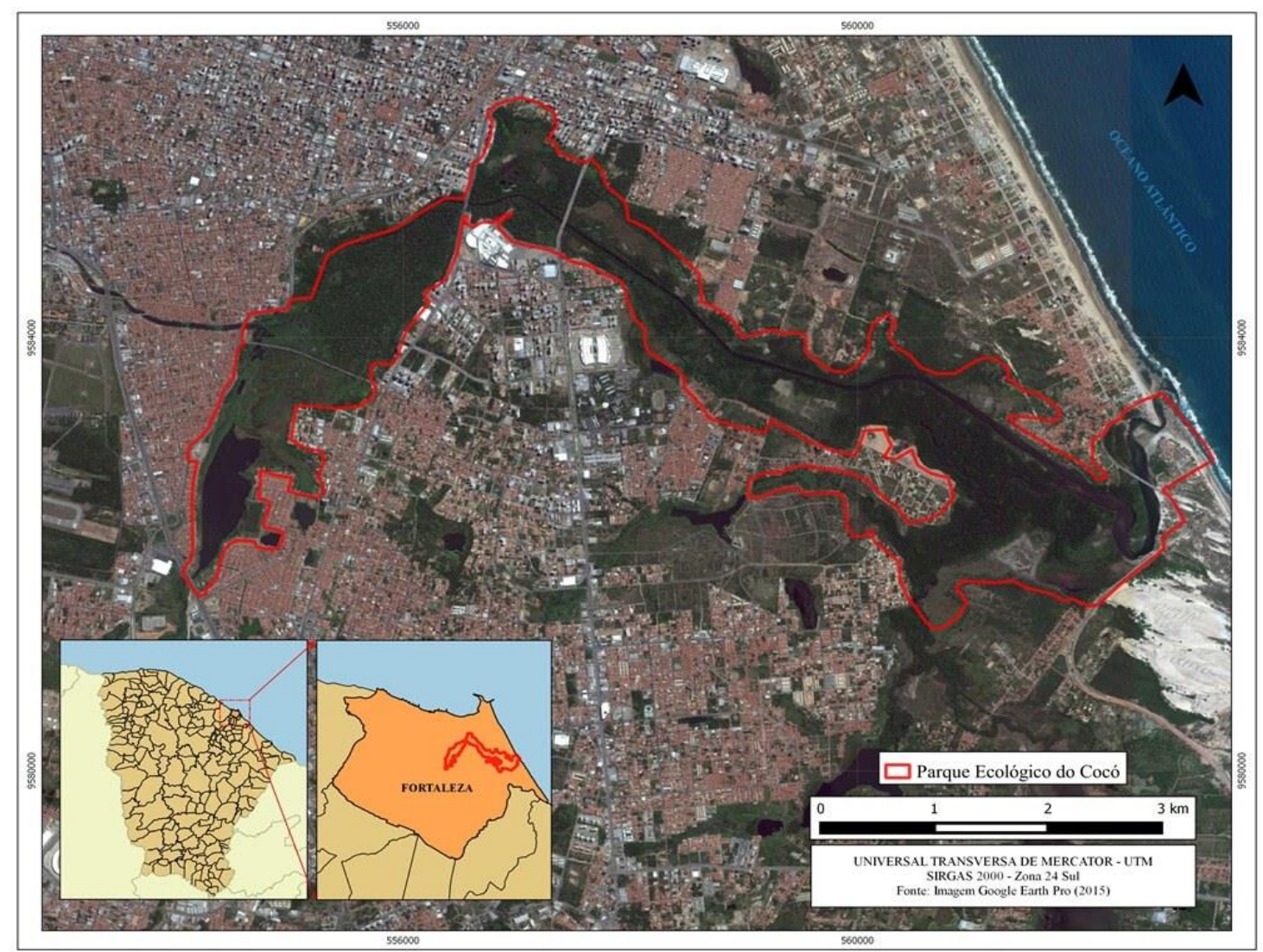

Figura 01. Mapa de localização do Parque Ecológico do Cocó, em Fortaleza (CE). Fonte: Elaborado pelo autor (2016).

No contexto ambiental, o PEC apresenta três unidades com características relevantes em todos os âmbitos a serem preservadas efetivamente: planície-fluvial, planície flúvio-marinha e a planície litorânea, especialmente área de dunas. Ambientes fortemente instáveis, configurando-se como vulneráveis à ocupação urbana (SOUZA, 2000).

Nas proximidades de sua foz do rio do Cocó apresenta um complexo estuarino que é considerado um berçário natural, devido sua elevada produtividade biológica e que se configura como um importante cenário na composição da cadeia alimentar, onde se desenvolvem formas representativas de manguezais, que desempenham funções ecológicas fundamentais para a regulação dos ambientes da região costeira tropical ${ }^{1}$. Segundo Rocha et al. (2008, p.3), “os manguezais servem de zona de desova e de alimento para inúmeras espécies de peixes, chegando a $80 \%$ dos recursos pesqueiros dependerem, direta ou indiretamente". Além de sua importância biológica, a exploração pelas populações ribeirinhas de peixes, camarões, caranguejos e ostras que correm nos manguezais, constituem uma importante fonte de renda e alimento (FERNANDES SOBRINHO, 2008).

\footnotetext{
${ }^{1}$ Além disso, os manguezais são considerados Áreas de Proteção Permanente (APP's), de acordo com a Lei No 12.651 , de 25 de maio de 2012. Art. $4^{\circ}$, inciso VII do Código Florestal.
} 
O referido parque abriga uma significativa parcela de área verde em plena malha urbana de Fortaleza, o que contribui tanto para o bem-estar da sociedade, principalmente, por seu papel termorregulador, quanto para a conservação das espécies (animais e vegetais) que vivem nesse habitat.

\subsection{Procedimentos metodológicos}

Foram consideradas algumas etapas, a fim de uma melhor interpretação. A primeira delas diz respeito ao levantamento e análise da legislação ambiental básica, a nível nacional, estadual e municipal, a citar o SNUC, Código Florestal, Plano Diretor de Fortaleza, entre outros.

Destaca-se que a revisão conceitual se deu a partir de consultas a artigos, monografias e dissertações que exploravam a temática em questão. Foram trabalhadas definições de Unidade de Conservação no SNUC, Áreas de Proteção Permanente pelo Código Florestal e os aspectos geoambientais, envolvendo a Bacia do Cocó, principalmente seu estuário. Ressalta-se, ainda, a discussão do conceito de comunidade tradicional e conflitos socioambientais para a interpretação desses impasses em áreas protegidas pela legislação.

Levando em consideração que a bacia hidrográfica enquanto unidade paisagística deve ser entendida de maneira integrada, a segunda etapa voltou-se aos aspectos geoambientais e sua importância para Fortaleza, como também os problemas que atingem os sistemas ambientais ao longo da bacia e trazem consequências até a sua foz. Destaca-se que foi realizado um trabalho de campo dentro dos limites do Parque para complementar a interpretação sob um olhar geográfico.

$\mathrm{Na}$ parte final desse estudo, buscou-se dimensionar tanto a proposta de delimitação física do Parque por parte do Governo, como os conflitos gerados a partir implantação do Parque Estadual do Cocó. Para isso, a elaboração de material cartográfico tomou como ponto de partida o mapa dos limites propostos pela SEMA, do qual foi georreferenciado para a vetorização da poligonal. E por fim, as margens foram sobrepostas à uma imagem de satélite retirada no Google Earth Pro, do ano de 2015.

\section{RESULTADOS E DISCUSSÃO}

Ao refazer um breve histórico das lutas em prol da regulamentação jurídica do Parque do Cocó, nota-se a falta de comprometimento por parte do Governo Estadual para a efetivação das propostas de implantação. Em 1986 foi assinado o primeiro decreto de proteção do Cocó, criando a Área de Proteção Ambiental do Vale do Cocó, com 700 hectares, dando primeiro impulso para a organização de movimento pela área verde na cidade, reivindicando a criação e delimitação do Parque do Cocó, no entorno do rio com o mesmo nome (NOTTINGHAM, 2006). 
Em 1989, por Decreto de Tasso Jereissati, à época governador, declara área de 1.046 hectares como de interesse social para fins de desapropriação. Quatro anos depois Ciro Gomes, que era governador, declara de interesse social para fins de desapropriação área de 1.155,2 hectares. Porém, as desapropriações a que os Decretos se referiam nunca foram efetivadas.

No intuito viabilizar as ações em prol da legalização do parque, o Ministério Público Federal no Ceará (MPF/CE) em manifesto divulgado no dia 20 de janeiro de 2015, estabeleceu o Fórum Permanente do Cocó. O Fórum Cocó reúne cerca de 20 entidades com o objetivo de subsidiar o Governo do Estado do Ceará no processo de tomada de decisão da delimitação, integrando estas áreas ao patrimônio ambiental, cultural, social e econômico da cidade de Fortaleza e do Estado.

No ano de 2016, após ser retomada a discussão sobre as propostas, o Governador do Estado do Ceará, Camilo Santana, propôs a tão ansiada assinatura do Decreto de criação do parque. No entanto, a oficialização do Decreto que estava marcada para o dia 05 de junho de 2016 foi adiada por tempo indeterminado, em virtude de questionamentos sobre a poligonal.

Diante do exposto, cabe salientar que as áreas verdes de Fortaleza vêm sendo suprimidas drasticamente nas últimas décadas. Em 1968, 65,79\% da cidade era ocupada por áreas verdes originais, passando a 16,64\%, em 1990, e em 2002, as áreas verdes ocupavam apenas 7,06\%. Destaca-se que em apenas 34 anos sua cobertura vegetal original encolheu 63\%, conforme os dados do Inventário ambiental de Fortaleza (FORTALEZA, 2003 apud, COSTA, 2014). Cita-se, ainda, que da porcentagem de vegetação que resta, a maioria está concentrada no PEC.

Atualmente, os sistemas ambientais do parque estão bastante modificados, contando com uma área de abrangência significativamente menor que da primeira proposta de conservação do ambiente. A planície do Rio Cocó se encontra totalmente degradada, devido despejo de resíduos sólidos e lançamento de efluentes de ligações clandestinas ao longo de toda a sua bacia hidrográfica. A prova disso é a elevada incidência de macrófitas aquáticas - consideradas bioindicadores de poluição hídrica - em todo curso urbano do rio.

No baixo curso, a degradação do ecossistema manguezal iniciou-se ainda no século XIX a partir da exploração da atividade salineira que perdurou por anos até o seu declínio. Foi um dos principais fatores que contribuíram para a degradação do ambiente estuarino (VIANA, 2003). Atualmente, uma série de outros fatores contribui para a devastação desse ambiente, com destaque para a forte pressão antrópica, advinda das atividades industriais, comércio e a ocupação residencial, que quando associadas às alterações naturais vêm causando considerável desequilíbrio ecológico na área. 
A falta de planejamento na expansão da malha urbana de Fortaleza tem sido o principal responsável pelo desequilíbrio dos ecossistemas. Essa questão denuncia em grande parte a ineficiência do sistema de saneamento básico, principalmente na cidade de Fortaleza onde há maior pressão demográfica sobre os recursos naturais, prejudicando o bem-estar humano e a qualidade ambiental.

A especulação imobiliária é outro fator preponderante na devastação dessas unidades geoambientais, através da apropriação do espaço mais nobre pela iniciativa privada. Como justifica Mendonça (2007), isso ocorre pois ao amenizarem o perturbado ambiente urbano, esses locais arborizados modificavam o percurso cotidiano do morador citadino, propiciando de imediato, a apropriação pelas elites. Estas, constroem edificações luxuosas exercendo uma pressão significativa nos ecossistemas. No caso do PEC, alguns prédios de grande estrutura que se encontram nos limites da unidade possuem até mesmo passagem direta para o interior do parque. Percebe-se, portanto, a utilização desse espaço para a valorização de grandes empreendimentos imobiliários para benefício particular.

Ao se tratar da problemática da delimitação do Parque Estadual do Cocó enquanto uma Unidade de Conservação, a poligonal abrangerá uma parcela de uma UC já instituída. A área em questão é reconhecida como Área de Proteção Ambiental (APA), administrada pelo Município de Fortaleza, enquadrada em Unidade de Uso Sustentável, cuja sua principal finalidade é servir como zona de amortecimento para o Parque Natural das Dunas de Sabiaguaba (decreto municipal $\mathrm{n}^{\circ}$ 11.986, de fevereiro de 2006).

A APA da Sabiaguaba abriga uma população que vive na foz do rio Cocó e se utiliza de seus recursos para subsistência. O impasse da efetivação da proposta do Parque Estadual do Cocó implicará na remoção de 150 famílias na comunidade da Boca da Barra na região da Sabiaguaba, configurando-se como uma zona de conflito (Figura 02). As famílias lutam para permanecer na região, onde a maioria já vive lá há gerações. Nestes casos, o âmbito cultural vinculado a identidade com o lugar se sobressai, gerando conflitos diante do exposto.

Em entrevista ao jornal O Povo, o geógrafo Jeovah Meireles ${ }^{2}$, que coordenou a execução do Plano de Manejo da APA da Sabiaguaba, defende a permanência da comunidade no local. O professor justifica ainda que a permanência da comunidade naquela região já foi chancelada por diversas instituições, como no próprio Plano de Manejo da Sabiaguaba.

\footnotetext{
${ }^{2}$ Professor do Departamento de Geografia da Universidade Federal do Ceará (UFC) e dos Programas de Pós-graduação em Geografia e em Desenvolvimento e Meio Ambiente (PRODEMA).
} 


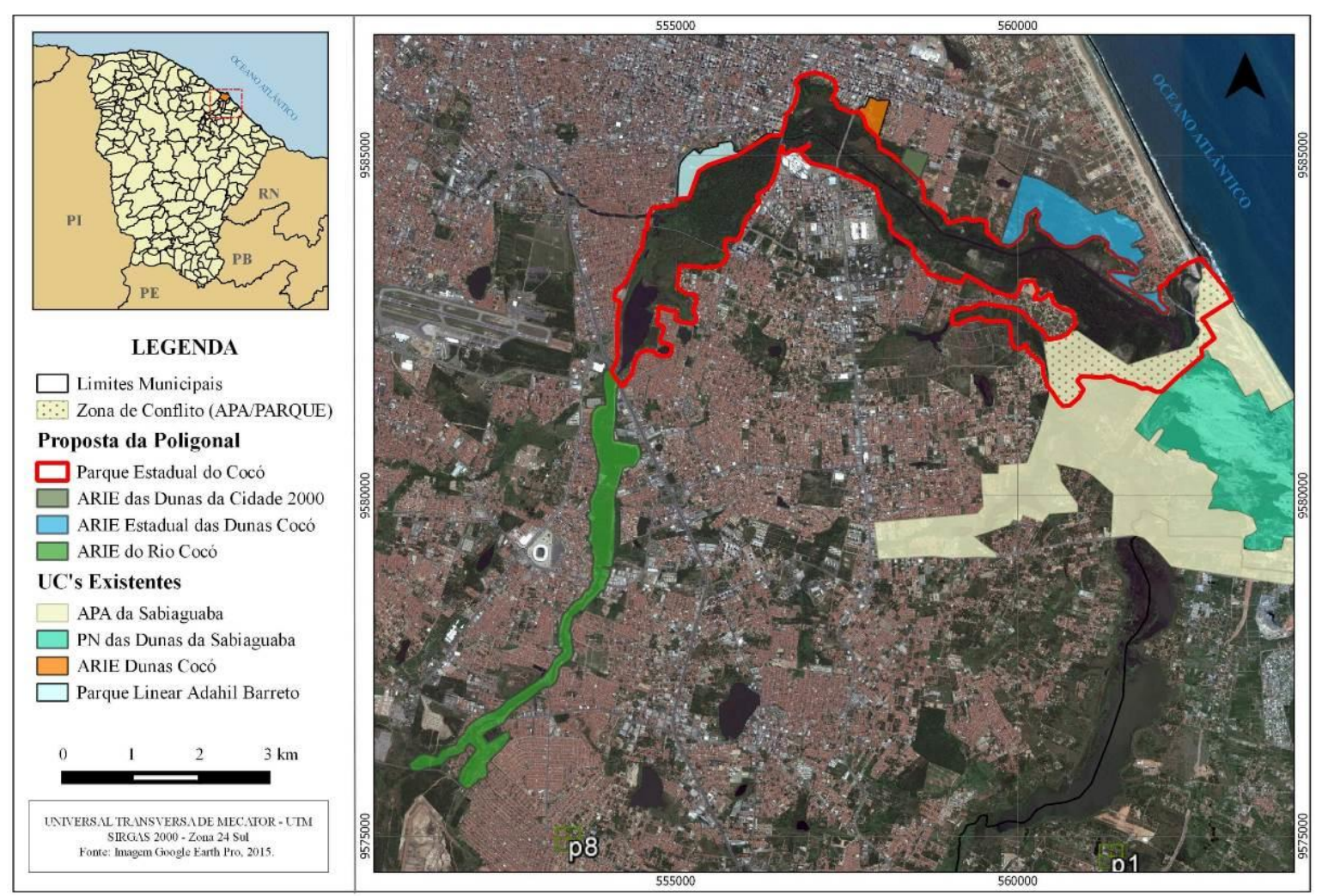

Figura 02. Mapa da proposta da Poligonal das Unidades de Conservação em Fortaleza (CE). Juntamente com as UC's já instituidas e a zona de conflito. Fonte: Elaborado pelo autor (2016).

Por outro lado, contraditoriamente, os interesses econômicos se sobressaem, à medida que três grandes áreas de dunas florestadas, com fauna e flora específicas e fundamentais para a dinâmica do parque, foram retiradas da poligonal que foi proposta pelo Fórum Cocó, e colocadas fora do limite oficial apresentado pelo Governo do Estado em audiência pública. A citar as três áreas são: Dunas do Cocó, Dunas da Cidade 2000 e as Dunas da Praia do Futuro. A justificativa por parte do Governo é a falta de recursos para as desapropriações da área, como determina a lei.

No entanto, há uma área específica que, mesmo não necessitando de desapropriação, está sendo deixada de fora da poligonal. $\mathrm{Na}$ área em questão está "coincidentemente" prevista a construção da Ponte Estaiada sobre o rio Cocó. A obra orçada em R \$ 338 milhões, sendo R \$ 259 milhões do Governo Federal e R \$ 79 milhões do estado do Ceará, vai ligar a Avenida Washington Soares ao Bairro Dunas na cidade de Fortaleza (G1, CEARÁ, 2016). Já o impacto ambiental é incalculável, tendo em vista que é uma obra de grande porte que fragmentará o parque.

A questão central apresenta-se entre o que é legal e o que é justo: é legal que essas comunidades continuem a morar e se utilizar da área que passará a ser Unidade de Proteção Integral? Sem dúvidas, perante a lei, a resposta é não. Mas, é justo que grandes áreas com características essenciais para serem preservadas sejam deixadas fora da poligonal para favorecer futuros empreendimentos, enquanto as pessoas que sempre se utilizaram do ambiente para subsistência estão ameaçadas de perder, mais do que suas casas, sua identidade com o local? 
Percebe-se, portanto, os conflitos que envolvem a ocupação do espaço urbano e os divergência de interesses estruturados dentro da questão ambiental, mais especificamente em Unidades de Conservação. A falta de planejamento urbano é um dos principais condicionantes para a ocupação irracional do ambiente, principalmente em áreas territorialmente protegidas que acabam por gerar conflitos em vários âmbitos.

\section{CONSIDERAÇÕES FINAIS}

Os fatores expostos acima justificam a necessidade da legitimação do Parque Estadual do Cocó em esfera jurídica. A implementação efetiva de Unidades de Conservação deve ser encorajada dada a forte degradação dos recursos naturais, principalmente em área urbana.

Quanto aos conflitos socioambientais, nota-se o favorecimento ao setor imobiliário, posto que em áreas onde a especulação imobiliária é forte, nem sequer foram postas na poligonal, mesmo contendo características suficientes para tal.

Enquanto isso, comunidades tradicionais sofrem a tensão de serem ameaçadas de perder suas casas, seus meios de sobrevivência e sua história. Populações estas que se utilizam do espaço e recursos naturais voltados para a subsistência, com o uso de mão-de-obra familiar, no qual ocupam a região há muito tempo e que, na maioria dos casos, os moradores se quer tem registro da propriedade para comprovar o domínio da terra.

É preciso, portanto, como um dos objetivos do SNUC visa, solucionar e minimizar os conflitos gerados pela implantação de Unidades de Conservação de Proteção Integral em territórios tradicionais, através de acordos em que sejam justos para os envolvidos.

\section{REFERÊNCIAS}

BRASIL. Constituição (1988). Constituição da República Federativa do Brasil. Brasília, DF: Senado Federal: Centro Gráfico, 1988. 292 p.

Decreto $n^{\circ}$ 6.040, de 7 de fevereiro de 2007. Institui a Política Nacional de Desenvolvimento Sustentável dos Povos e Comunidades Tradicionais. Brasília, DF: Palácio do Planalto, 2007.

Lei $\mathrm{n}^{\circ} 9.985$ de 18 de julho de 2000. Regulamenta o art. 225, § 1o, incisos I, II, III e VII da Constituição Federal, institui o Sistema Nacional de Unidades de Conservação da Natureza e dá outras providências. Brasília, DF: Palácio do Planalto, 2000.

Ministério Público Federal. Fórum Permanente pela implantação o "Parque Ecológico Do Cocó”. 2016.

BRITO, D.M.C.; BASTOS, C.M.C.B.; FARIAS, R.T.S.; BRITO, D.C.; DIAS, G.A.C. Conflitos socioambientais no século XXI. PRACS: Revista Eletrônica de Humanidades do Curso de Ciências Sociais da UNIFAP, v. 4, p. 51-58, 2011. 
CEARÁ. Superintendência Estadual do Meio Ambiente - SEMACE. Parque Ecológico do Rio Cocó. Fortaleza, 2016.

COSTA, A. Demandas do movimento ambiental por áreas verdes em Fortaleza - Fortaleza: Banco do Nordeste do Brasil, 2014.

COSTA, R.G.S.; FERREIRA, C.C.M. Análise do Índice de Áreas Verdes (Iav) na área central da cidade de Juiz de Fora, MG. REVSBAU, Piracicaba - SP, v.4, n.1, p.39-57, 2009.

FERNANDES SOBRINHO, M. Aspectos Geoambientais do Mangue Do Rio Cocó: Um Estudo de Caso. 2008. 66 f. Monografia (especialização) - Centro de Estudos Sociais Aplicados, da Universidade Estadual do Ceará, Fortaleza, 2008.

O Povo Online. IMPASSE sobre remoção de comunidade adia regulamentação do Cocó. Fortaleza, 03 jun. $2016 . \quad$ Disponível em: http://www.opovo.com.br/app/opovo/cotidiano/2016/06/03/noticiasjornalcotidiano,3619891/impass e-sobre-remocao-de-comunidade-adia-regulamentacao-do-coco.shtml >. Acesso em: 28 jun. 2016.

MARTINS, Andreza. Conflitos ambientais em unidades de conservação: dilemas da gestão territorial no Brasil. Revista bibliográfica de geografia y ciências sociales Universidad de Barcelona Cuadernos Críticos de Geografia Humana, v. 17, n. 989, 2012.

MENDONÇA, E.M.S. Apropriações do espaço público: alguns conceitos. Estudos e Pesquisas em Psicologia (Online), v. 2, p. 122-132, 2007.

MP do Ceará quer anular licitação da Ponte Estaiada por irregularidades. G1 Ceará. Fortaleza, 29 abr. 2016. Disponível em: < http://g1.globo.com/ceara/noticia/2016/04/mp-do-ceara-quer-anularlicitacao-da-ponte-estaiada-por-irregularidades.html >. Acesso em: 30 jun. 2016.

NOTTINGHAM, P. C. Tempos verdes em Fortaleza: um olhar sobre a experiência do movimento ambientalista (1976-1992). 2006. Dissertação (Mestrado em História Social) - Universidade Federal do Ceará, Fortaleza, 2006. 203 p.

ROCHA, D.A.; MEIRELES, A.J.A.; FROTA, H.B. Ecossistema Manguezal do Rio Cocó e o Licenciamento Ambiental do Iguatemi Empresarial, em Fortaleza/CE. In: Anais Congresso LatinoAmericano de Direitos Humanos e Pluralismo Jurídico, 2008, Florianópolis. Florianópolis: Editora Dom Quixote, 2008.

SOUZA, Marcos José Nogueira de. Bases naturais e esboço do zoneamento geoambiental do Estado do Ceará. In: LIMA, L. C.; SOUZA, M. J. N.; MORAIS, J. O. Compartimentação territorial e gestão regional do Ceará. Fortaleza: FUNECE, 2000.

VIANA, M. C. Estudo da degradação no manguezal do Rio Cocó - Fortaleza/CE. Revista da Casa da Geografia de Sobral, Sobral, v. 4/5, p. 55-65, 2002/2003.

\section{AGRADECIMENTOS}

À equipe do Laboratório de Geoprocessamento e Estudos Aplicados - LABGEO. Ao Prof. Dr. Luiz Cruz Lima, atual representante da Universidade Estadual do Ceará (UECE) no Fórum Cocó, por disponibilizar toda a base bibliográfica e documental pertinentes à temática.

Recebido em: 14/08/2016

Aceito para publicação em: 01/10/2016 